\title{
Coverage of the WHO's four essential elements of newborn care and their association with neonatal survival in southern Nepal
}

Emily Bryce ${ }^{1 *} \mathbb{D}$, Luke C. Mullany ${ }^{1}$, Subarna K. Khatry ${ }^{1,2}$, James M. Tielsch ${ }^{3}$, Steven C. LeClerq ${ }^{1,2}$ and Joanne Katz ${ }^{1}$

\begin{abstract}
Background: Despite recent improvements in child survival, neonatal mortality continues to decline at a slower rate and now represents $47 \%$ of under-five deaths globally. The World Health Organization developed core indicators to better monitor the quality of maternal and newborn health services. One such indicator for newborn health is "the proportion of newborns who received all four elements of essential care". The four elements are immediate and thorough drying, skin to skin contact, delayed cord clamping, and early initiation of breastfeeding. Although there is existing evidence demonstrating an association with decreased neonatal mortality for each element individually, the cumulative impact has not yet been examined.
\end{abstract}

Methods: This analysis uses data from a randomized trial to examine the impact of sunflower versus mustard seed oil massage on neonatal mortality and morbidity in the Sarlahi district in Southern Nepal from 2010 to 2017. The proportion of newborn infants receiving an intervention was the exposure and neonatal mortality was the outcome in this analysis. Neonatal mortality was defined as a death between three hours and less than 28 days of age. Associations between neonatal mortality and the essential elements were estimated by Cox proportion hazards models. The hazard ratios and corresponding 95\% confidence intervals were reported.

Results: 28,121 mother-infant pairs and 753 neonatal deaths were included. The percent receiving the individual elements ranged from $19.5 \%$ (skin to skin contact) to $68.2 \%$ (delayed cord clamping). The majority of infants received one or two of the elements of essential care, with less than $1 \%$ receiving all four. Skin to skin contact and early initiation of breastfeeding were associated with lower risk of neonatal mortality (aHR $=0.64[0.51,0.81]$ and $\mathrm{aHR}=0.72[0.60,0.87]$, respectively). The risk of mortality declined as the number of elements received increased; receipt of one element compared to zero was associated with a nearly $50 \%$ reduction in risk of mortality and receipt of all four elements resulted in a $72 \%$ decrease in risk of mortality.

Conclusions: The receipt of one or more of the four essential elements of newborn care was associated with improved neonatal survival. The more elements of care received, the more survival improved.

Keywords: Neonatal mortality, Immediate drying, Skin to skin contact, Cord clamping, Early initiation of breastfeeding

\footnotetext{
* Correspondence: ebryce2@jhmi.edu

'Department of International Health, Johns Hopkins Bloomberg School of

Public Health, 615 N. Wolfe Street, Baltimore, MD 21205, USA

Full list of author information is available at the end of the article
}

(c) The Author(s). 2020 Open Access This article is licensed under a Creative Commons Attribution 4.0 International License, which permits use, sharing, adaptation, distribution and reproduction in any medium or format, as long as you give appropriate credit to the original author(s) and the source, provide a link to the Creative Commons licence, and indicate if changes were made. The images or other third party material in this article are included in the article's Creative Commons licence, unless indicated otherwise in a credit line to the material. If material is not included in the article's Creative Commons licence and your intended use is not permitted by statutory regulation or exceeds the permitted use, you will need to obtain permission directly from the copyright holder. To view a copy of this licence, visit http://creativecommons.org/licenses/by/4.0/. The Creative Commons Public Domain Dedication waiver (http://creativecommons.org/publicdomain/zero/1.0/) applies to the data made available in this article, unless otherwise stated in a credit line to the data. 


\section{Background}

Between 1990 and 2017 the global under-five mortality rate declined by $58 \%$ and the neonatal mortality rate by $51 \%$ [1]. Despite this progress, neonatal mortality continues to decline at a slower rate than under-five mortality and both measures remain well above the Sustainable Development Goal (SDG) targets for 2030 [1, 2]. Nepal was one of the few countries that achieved the antecedent Millennium Development Goal's (MDG) fourth target, with the under 5 mortality rate declining from 162 to 38 deaths per 1000 live births. During the same time period, neonatal mortality in Nepal declined from 39 to 23 deaths per 1000 live births [3, 4].

In an effort to continue the progress made in reducing maternal, child and neonatal mortality, the global community has recognized that in going forward with the SDGs there needs to be a focus on quality of care measurement [5]. For this purpose, the World Health Organization (WHO) developed and released a list of global indicators for maternal and newborn care in 2014, one of which is the "proportion of newborns who received all four elements of essential care", which are as follows: immediate and thorough drying, immediate skin-to-skin contact, delayed cord clamping and initiation of breast feeding within the first hour [6].

Immediate and thorough drying (ITD) of the infant serves two purposes in reducing neonatal mortality: aiding in stimulation/resuscitation and thermal regulation of infants [7]. Roughly 10 million babies annually will require simple stimulation, which includes ITD, in order to begin breathing [8]. Neonatal hypothermia has been shown to be associated with higher risk of mortality and morbidity, particularly in preterm and low birthweight infants [9-11]. The primary source of heat loss for a newborn is the evaporation of amniotic fluid from the baby's skin. Often, a newborn's temperature drops 3$4{ }^{\circ} \mathrm{C}$ within minutes after being born [12]. This almost immediate change in temperature highlights the importance of ITD to reduce the presence of amniotic fluid on the baby's body.

Skin to skin contact (SSC) is important for establishing breastfeeding practices, thermal regulation of a newborn, and transfer of normal skin flora from mother to infant. Infants who experienced SSC were more likely to be breastfed one to four months postpartum, to be exclusively breastfed at six weeks to six months, and breastfeed more effectively $[13,14]$. The second most common source of heat loss for a newborn is via conduction, or being placed on a cold surface [12]. Immediate SSC ensures that the baby is placed on a warm surface, their mother's chest. SSC is recommended for hypothermia prevention and has been shown to be at least as effective in temperature maintenance in newborns as conventional incubators $[12,15]$.
The third element in the WHO's package of essential elements for newborn care is delayed cord clamping (DCC), which is defined as the severing of the umbilical cord at least one minute after delivery or when the umbilical cord is no longer pulsating [16]. DCC allows the newborn to continue receiving fetal blood from the placenta after delivery, which can result in $60 \%$ more red blood cells and a 30\% increase in blood volume [17]. Other suggested benefits of DCC include increased hemoglobin concentrations, reduced rates of anemia, improved cardiopulmonary adaptation, and better iron status in infants six months postpartum $[17,18]$.

Early initiation of breastfeeding (EIB) is defined as initiation of breastfeeding within the first hour after delivery. There is substantial evidence demonstrating that breastfeeding, specifically exclusive breastfeeding for six months, is a cheap and effective way to reduce all-cause and infection-related infant mortality [19]. Recently, there has been a shift in focus to the timing of breastfeeding initiation. Early initiation has been shown to result in an increased duration of and exclusivity of breastfeeding [20, 21]. Furthermore, beginning to breastfeed within the first hour also ensures that the baby is exposed to colostrum, which is associated with improved development of the intestinal mucosal and immunological protections [22].

The logic is that neonates who receive all four essential elements are more likely to survive than those who do not, given the pre-existing evidence base for the individual elements. As the indicator was recently developed, there has been limited research conducted looking at the four elements together. This paper will examine the current coverage of each individual element, distribution of number of elements received, associated characteristics with receipt of each element, and the association(s) between the element(s) and neonatal mortality in Sarlahi district of Nepal.

\section{Methods}

\section{Parent trial}

The data used for this analysis were originally collected as part of a cluster-randomized community based trial (ClinicalTrials.gov, NCT01177111) on the impact of sunflower seed oil versus standard of care mustard seed oil massage on neonatal mortality and morbidity. This study, conducted in Sarlahi district, Nepal, consented and enrolled incident pregnancies and followed the women through delivery and 28 days postpartum [23]. Data on the four elements were collected through postpartum interviews and neonatal mortality data through verbal autopsy interviews, $75 \%$ of which were with the mothers. In those instances, the neonatal verbal autopsy interview was completed with a family member These interviews were conducted as soon as possible and 
appropriate (death) after the event. About $80 \%$ were visited within 72-h of birth and $80 \%$ within a month of death.. Maternal characteristics were collected at enrollment in the parent study.

\section{Analysis overview}

The element "immediate and thorough drying" was defined as whether the baby was completely wiped with a cloth prior to placental delivery. An infant was considered to have received the "immediate skin to skin contact" element if they were placed on the mother's chest and/or in her arms before delivery of the placenta. In the parent trial, exact time to cord clamping was not collected, therefore for this analysis "delayed cord clamping" was defined as clamping the umbilical cord after the placenta was delivered. "Early initiation of breastfeeding" was defined as the infant initiating breastfeeding within the first hour postpartum. Associations between maternal-infant characteristics and receipt of the four elements were examined using log binomial regression.

The main outcome of interest was neonatal mortality defined as a death between $3 \mathrm{~h}$ and 28 days of age. To account for reverse causality, infants who died within $3 \mathrm{~h}$ of birth were removed from the analysis, as it is possible that their status immediately postpartum may have impacted the likelihood of receiving the four essential elements. A total of 28,121 mother-infant pairs where the infant survived at least three hours postpartum and 753 neonatal deaths were included in the analysis. The choice of $3 \mathrm{~h}$ as the cut off was arbitrary, but a sensitivity analysis was conducted using 2 and 4 h cut offs and found that this did not significantly change the estimated hazard ratios for any of the four elements (Supplemental Table 1). For the same reason, multiple births and mother-infant dyads where the mother died during childbirth were also removed from the analysis. Therefore, singleton, live-born infants that survived beyond three hours postpartum and their mothers who survived childbirth were included in the analysis.

To examine the relationship between an individual element and neonatal mortality, all observations for the element were included in the analysis, irrespective of values of the other elements (received, not received, or missing). For analyses where all four elements are included in the model, only those infant-mother pairs with no missing data on the four elements are included. The same is true for the analyses examining number of elements received (0-4) and mortality, as to not assume that a "don't know" response means that the infant did not receive the element.

As a sensitivity analysis, mortality was examined for infants who survived more than two days. The restriction to at least two-day survival is of interest because all four interventions may not have an immediate effect on mortality, rather the impact may be seen in longer-term survival rates. This also allowed for the removal of a more extreme reverse causality potentially present in this analysis.

Coverage of each element was calculated, as was the distribution of infants receiving none, one, two, three and all four of the elements. Coverage was defined as all of those in need of an intervention (in the analysis, live born singleton infants) who received an intervention (the essential elements) [24].

Mortality was examined using live births that survived beyond three hours postpartum as the denominator and deaths between three hours and 28 days as the numerator. Mortality rates for infants who received each element were reported, as well as hazard ratios estimated using a Cox proportional hazard model (with the Efron method for ties) to determine the relationship between mortality and the four elements after controlling for potential confounders. The covariates included sex of infant, preterm birth ( $<37$ weeks gestation), mother's literacy, a socioeconomic composite score divided into quartiles, parity (first birth vs. not) and whether the birth took place in a facility.

The DDC and EIB elements violated the proportional hazards assumption for the Cox model, assessed by Schoenfeld residual plots and proportionality tests. To correct for this, the analyses for these two elements were stratified by time, less than three days postpartum and greater than three days postpartum. The model with all four elements included was also stratified to maintain the proportional hazards assumption.

All analyses were conducted using Stata version 14.2 (Stat Corp, College Station, Texas). The Institutional Review Board of the Johns Hopkins Bloomberg School of Public Health (Baltimore, Maryland) and the Ethical Review Committee of the Institute of Medicine, Tribhuvan University (Kathmandu, Nepal) approved the parent study.

\section{Results \\ Study population}

A total of 28,121 mother-infant pairs where the singleton infant survived at least three hours postpartum were included in the analysis, resulting in a total analysis time of 757,605 days. There were 753 neonatal deaths (death after $3 \mathrm{~h}$ and by 28 days postpartum), resulting in an overall neonatal mortality rate for infants surviving beyond three hours postpartum of 26.8 neonatal deaths per 1000 live births. Were 814 infants that were lost to follow up during the 28-day period, equaling 11,383 days lost to follow-up.

Table 1 summarizes the characteristics of the motherinfant pairs in the analysis set. Comparing facility and non-facility births, a higher proportion of facility-born 
Table 1 Characteristics of mother-infant pairs

\begin{tabular}{|c|c|c|c|c|c|c|}
\hline & $\begin{array}{l}\text { All mother-infant } \\
\text { pairs } \mathrm{n}(\%) \\
N=28,121\end{array}$ & $\begin{array}{l}\text { Immediate and thorough } \\
\text { drying } \mathrm{n}(\%) \\
N=10,914\end{array}$ & $\begin{array}{l}\text { Skin to skin } \\
\text { contact } \mathrm{n}(\%) \\
N=5324\end{array}$ & $\begin{array}{l}\text { Delayed cord } \\
\text { clamping } \mathrm{n}(\%) \\
N=18,252 \\
\end{array}$ & $\begin{array}{l}\text { Early initiation of } \\
\text { breastfeeding } \mathrm{n}(\%) \\
N=8459\end{array}$ & $\begin{array}{l}\text { Mortality } \\
\mathrm{n}(\%) \\
N=753 \\
\end{array}$ \\
\hline \multicolumn{7}{|l|}{ Sex of infant } \\
\hline Male & 14,528 (51.7\%) & $5723(41.3 \%)$ & $2872(20.4 \%)$ & 9225 (66.8\%) & $\begin{array}{l}4583 \\
(31.6 \%)\end{array}$ & $\begin{array}{l}401 \\
(2.8 \%)\end{array}$ \\
\hline Female & 13,593 (48.3\%) & 5191 (39.8\%) & 2452 (18.54\%) & 9027 (69.6\%) & $\begin{array}{l}3876 \\
(28.5 \%)\end{array}$ & $\begin{array}{l}352 \\
(2.6 \%)\end{array}$ \\
\hline \multicolumn{7}{|l|}{ Preterm birth } \\
\hline$>37$ weeks & $22,698(81.0 \%)$ & 8934 (41.1\%) & 4483 (20.3\%) & $14,524(67.2 \%)$ & $\begin{array}{l}6976 \\
(30.8 \%)\end{array}$ & $\begin{array}{l}442 \\
(1.9 \%)\end{array}$ \\
\hline$<37$ weeks & 5324 (19.0\%) & 1944 (38.3\%) & 821 (15.9\%) & 3653 (72.2\%) & $\begin{array}{l}1455 \\
(27.4 \%)\end{array}$ & $\begin{array}{l}306 \\
(5.8 \%)\end{array}$ \\
\hline \multicolumn{7}{|c|}{ Mother's literacy } \\
\hline Literate & $8814(31.3 \%)$ & 3872 (47.2\%) & $2378(28.3 \%)$ & 4417 (54.3\%) & $\begin{array}{l}3097 \\
(35.2 \%)\end{array}$ & $\begin{array}{l}198 \\
(2.3 \%)\end{array}$ \\
\hline Illiterate & $19,300(68.7 \%)$ & 7038 (37.7\%) & 2943 (15.6\%) & 13,832 (74.2\%) & $\begin{array}{l}5359 \\
(27.8 \%)\end{array}$ & $\begin{array}{l}555 \\
(2.9 \%)\end{array}$ \\
\hline \multicolumn{7}{|l|}{ SES quartile } \\
\hline First & 9609 (34.2\%) & 3445 (36.9\%) & $1332(14.1 \%)$ & 7132 (76.4\%) & $\begin{array}{l}2613 \\
(27.2 \%)\end{array}$ & $\begin{array}{l}286 \\
(3.0 \%)\end{array}$ \\
\hline Second & 6056 (21.5\%) & 2352 (40.4\%) & 1067 (18.1\%) & 3965 (68.4\%) & $\begin{array}{l}1796 \\
(29.7 \%)\end{array}$ & $\begin{array}{l}174 \\
(2.9 \%)\end{array}$ \\
\hline Third & $5773(20.5 \%)$ & 2265 (41.2\%) & 1216 (21.7\%) & 3579 (65.6\%) & $\begin{array}{l}1767 \\
(30.7 \%)\end{array}$ & $\begin{array}{l}135 \\
(2.3 \%)\end{array}$ \\
\hline Fourth & $6683(23.8 \%)$ & 2852 (45.87\%) & 1709 (26.9\%) & 3576 (57.8\%) & $\begin{array}{l}2283 \\
(34.2 \%)\end{array}$ & $\begin{array}{l}158 \\
(2.4 \%)\end{array}$ \\
\hline \multicolumn{7}{|l|}{ Parity } \\
\hline Nulliparous & 7886 (28.0\%) & 3383 (46.1\%) & 1944 (25.9\%) & 4096 (56.3\%) & $\begin{array}{l}2256 \\
(28.6 \%)\end{array}$ & $\begin{array}{l}279 \\
(3.5 \%)\end{array}$ \\
\hline Multiparous & $20,234(72.0 \%)$ & 7531 (38.6\%) & 3379 (17.1\%) & 14,156 (72.6\%) & $\begin{array}{l}6203 \\
(30.7 \%)\end{array}$ & $\begin{array}{l}474 \\
(2.3 \%)\end{array}$ \\
\hline \multicolumn{7}{|l|}{ Place of delivery } \\
\hline $\begin{array}{l}\text { Hospital/ } \\
\text { clinic }\end{array}$ & $11,875(42.2 \%)$ & 6376 (59.6\%) & 5021 (45.3\%) & 2341 (22.1\%) & $\begin{array}{l}4876 \\
(41.1 \%)\end{array}$ & $\begin{array}{l}355 \\
(3.0 \%)\end{array}$ \\
\hline $\begin{array}{l}\text { At home/ } \\
\text { other }\end{array}$ & 16,245 (57.8\%) & 4537 (28.1\%) & 303 (1.9\%) & 15,911 (98.2\%) & $\begin{array}{l}3583 \\
(22.1 \%)\end{array}$ & $\begin{array}{l}398 \\
(2.5 \%)\end{array}$ \\
\hline
\end{tabular}

infants received ITD, SSC and EIB. However, 98.2\% of non-facility births received DCC, compared to only $22.1 \%$ of facility births. A higher proportion of preterm infants died than non-preterm infants. A separate analysis (Supplemental Table 2) examined relationships between characteristics and element receipt and found facility birth, mother's literacy and parity to have the strongest associations.

\section{Coverage}

The element coverage is displayed in Fig. 1. Delayed cord clamping had the highest coverage (68.2\%) and skin to skin contact has the lowest (19.5\%). The majority of infants received one or two elements, 48.1 and $37.2 \%$, respectively (Table 2). 11.0\% of infants received three of the elements and $0.9 \%$ received all four. Finally, $2.8 \%$ of infants received none of the essential elements.

\section{Essential element(s) association(s) with neonatal mortality} Bivariate Cox proportional hazards analyses examined the unadjusted associations of the elements with neonatal mortality and showed a protective effect for two of the four elements (Table 3). EIB was associated with the largest reduction in risk of neonatal mortality $(\mathrm{HR}=0.68$ $[0.56,0.82])$. SSC was associated with $22 \%$ reduction in risk of mortality.

Multivariable survival analyses were conducted for all infants who survived past three hours postpartum for the four elements separately (Table 3, all variables in Supplemental Table 3). Adjusting for potential 


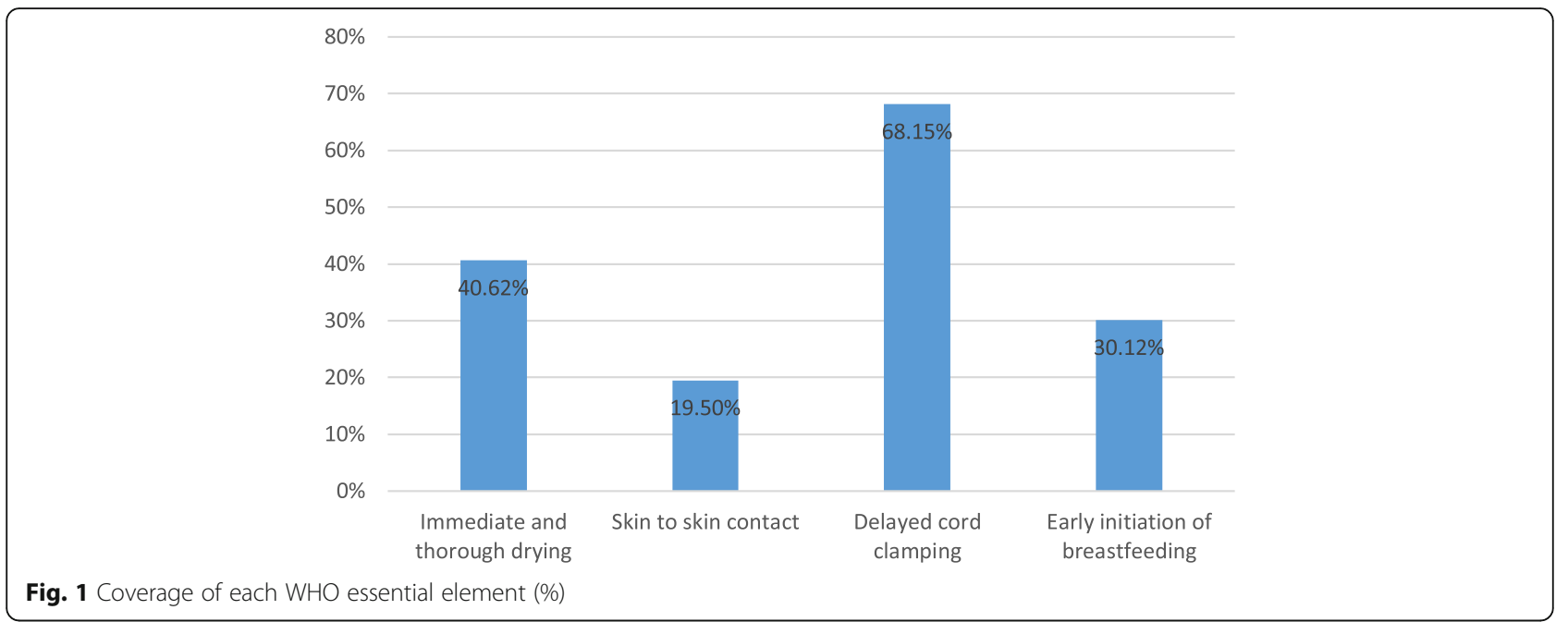

confounders, three of the four elements were associated with a reduction in mortality risk. The hazard ratio associated with EIB was slightly attenuated after adjustment, to a $28 \%$ reduction in risk of neonatal mortality. The magnitude of the $\mathrm{HR}$ for SSC increased $(\mathrm{aHR}=0.64$ $[0.51,0.81])$. A small positive association between ITD and neonatal mortality remained after adjustment, though it is statistically insignificant. The separate analysis for infants who survived past 48-h (Supplemental Table 5) attenuated the associations of two of the elements with risk of mortality; SSC remained the only significant element with an $\mathrm{aHR}=0.66[0.49,0.90]$. The DCC-mortality association qualitatively changed, now positive in the post-48-h survival group along with ITD.

The four elements were found to be correlated with one another (Supplemental Table 5, correlation range $[-0.4953,0.1493])$. Therefore, a model was fit to include all elements to assess the impact of each element controlling for the others in the three-hour and the 48-h survival groups (Supplemental Table 6). However, for ITD and DCC the adjustment for the other elements had little to no effect on the point estimates compared to the single-element models in both survival-time groups. The point estimates for SSC and EIB were attenuated slightly, a relative $\sim 10 \%$ decrease in estimated hazard ratios.

Table 2 Distribution of four elements in population

\begin{tabular}{lll}
\hline $\begin{array}{l}\text { Number of WHO essential elements of } \\
\text { newborn care received }\end{array}$ & $\begin{array}{l}\text { Coverage } \\
(\%)\end{array}$ & $\begin{array}{l}\text { Total } \\
\text { (n) }\end{array}$ \\
\hline 0 & $2.8 \%$ & 736 \\
1 & $48.1 \%$ & 12,638 \\
2 & $37.2 \%$ & 9783 \\
3 & $11.0 \%$ & 2911 \\
4 & $0.9 \%$ & 227 \\
\hline
\end{tabular}

Risk of neonatal morality associated with each element was stratified by preterm birth status, given its significance in the single element models and its known association with mortality (Supplemental Table 7). All four elements demonstrated a protective effect against neonatal mortality in the preterm infants, however these associations were not significant, likely due to sample size limitations.

\section{Number of elements received and associated mortality}

The association between the number of essential elements received and neonatal mortality (as defined as a death between three hours and less than 28 days) was also examined through bivariate and multivariable Cox proportional hazards models (Table 4, Fig. 2). Both analyses demonstrate that the associated risk of mortality decreased as the number of essential elements received increased. Compared to infants who received no essential elements, receiving one element was associated with a nearly $50 \%$ decrease in mortality. Receipt of two and three elements had an even larger reduction in mortality risk $(\mathrm{aHR}=0.46$ and $\mathrm{aHR}=0.34$, respectively). Infants who received all four elements had the largest reduction in risk of mortality $(72 \%)$ compared to infants who received none. However, very few infants received all four elements in this population.

\section{Discussion}

This analysis demonstrated that the greater the number of WHO's elements of essential newborn care that an infant receives, the lower their associated risk of mortality. The analysis also showed that despite these elements being recommended by the WHO, their coverage is quite variable in this population in rural Southern Nepal.

In the adjusted models, skin to skin contact, delayed cord clamping, and early initiation of breastfeeding were all associated with lower risks of mortality, whereas 
Table 3 Mortality risk by essential element, unadjusted and adjusted ${ }^{a}$

\begin{tabular}{|c|c|c|c|c|c|c|c|}
\hline Indicator & $\mathrm{n}$ & Died, $n$ & Mortality Rate & HR & $95 \% \mathrm{Cl}$ & aHR & $95 \% \mathrm{Cl}$ \\
\hline Immediate and thorough drying & & & & 1.11 & $(0.95,1.29)$ & 1.09 & $(0.93,1.27)$ \\
\hline Received & 10,914 & 295 & 27.0 per 1000 live births & & & & \\
\hline Did not receive & 15,954 & 390 & 24.4 per 1000 live births & & & & \\
\hline Skin to skin contact & & & & $0.78^{*}$ & $(0.64,0.95)$ & $0.64^{* *}$ & $(0.51,0.81)$ \\
\hline Received & 5324 & 113 & 21.2 per 1000 live births & & & & \\
\hline Did not receive & 21,980 & 596 & 27.1 per 1000 live births & & & & \\
\hline Delayed cord clamping & & & & 1.05 & $(0.90,1.23)$ & 0.87 & $(0.66,1.14)$ \\
\hline Received & 18,252 & 425 & 23.3 per 1000 live births & & & & \\
\hline Did not receive & 8530 & 247 & 29.0 per 1000 live births & & & & \\
\hline Early Initiation of Breastfeeding & & & & $0.68^{* *}$ & $(0.56,0.82)$ & $0.72^{* *}$ & $(0.60,0.87)$ \\
\hline Received & 8459 & 139 & 16.4 per 1000 live births & & & & \\
\hline Did not receive & 19,624 & 614 & 31.3 per 1000 live births & & & & \\
\hline
\end{tabular}

immediate and thorough drying was associated with a slight increased risk of mortality. As ITD is often included in a package of practices for neonatal resuscitation, there are few papers examining this single element's impact on neonatal mortality. One study that examined the 2006 WHO recommendations for newborn care using data from the 2011 Bangladesh DHS also found an increased, but statistically insignificant, risk of neonatal mortality associated with drying within five minutes of delivery $(\mathrm{OR}=1.64,0.75,3.58)$ [25]. A possible explanation for the increased associated risk of death for this element is that infants who were having difficulty breathing were more likely to receive ITD as part of the neonatal resuscitation procedure. Infants with issues breathing initially have been shown to be at a higher risk for mortality, confounding the impact for this element [26]. In the stratified analysis, ITD was associated with an insignificant reduction in mortality for preterm infants. As demonstrated by Mullany et al., preterm infants are at the highest risk of hypothermiarelated mortality which is the other pathway through which ITD is hypothesized to offer a protective effect [26].

Skin to skin contact and early initiation of breastfeeding were consistently associated with a reduction in neonatal mortality in this analysis. There is a substantial amount of evidence supporting EIB as a simple, effective tool to reduce neonatal mortality, consistent with the findings presented here [22]. Skin to skin contact as part of kangaroo mother care has been shown to reduce mortality in low birthweight infants as well as improve breastfeeding practices $[13,27,28]$. In the model that included all four elements, both SSC and EIB demonstrated a significant reduction in risk of neonatal mortality (defined as death between three hours and 28 days postpartum) after controlling for the other elements and covariates, indicating that despite the relationship between the two elements, they both offer protective effects independent of the other.

The association between risk of mortality and delayed cord clamping was inconsistent across the models. This is congruent with other findings in both term and

Table 4 Unadjusted and adjusted ${ }^{a}$ mortality by distribution of elements in infants surviving more than three hours

\begin{tabular}{|c|c|c|c|c|c|c|}
\hline & $\mathbf{N}$ & Mortality & HR & $95 \% \mathrm{Cl}$ & aHR & $95 \% \mathrm{Cl}$ \\
\hline Received zero of the four elements & 736 & 40 & Ref & Ref & Ref & Ref \\
\hline One element & 12,638 & 324 & $0.46^{* *}$ & $(0.33,0.64)$ & $0.51^{* *}$ & $(0.36,0.71)$ \\
\hline Two elements & 9783 & 226 & $0.42^{* *}$ & $(0.30,0.58)$ & $0.46^{* *}$ & $(0.33,0.65)$ \\
\hline Three elements & 2911 & 50 & $0.31^{* *}$ & $(0.20,0.47)$ & $0.34^{* *}$ & $(0.23,0.52)$ \\
\hline Four elements & 227 & 3 & $0.24^{*}$ & $(0.07,0.76)$ & $0.28^{*}$ & $(0.09,0.89)$ \\
\hline
\end{tabular}




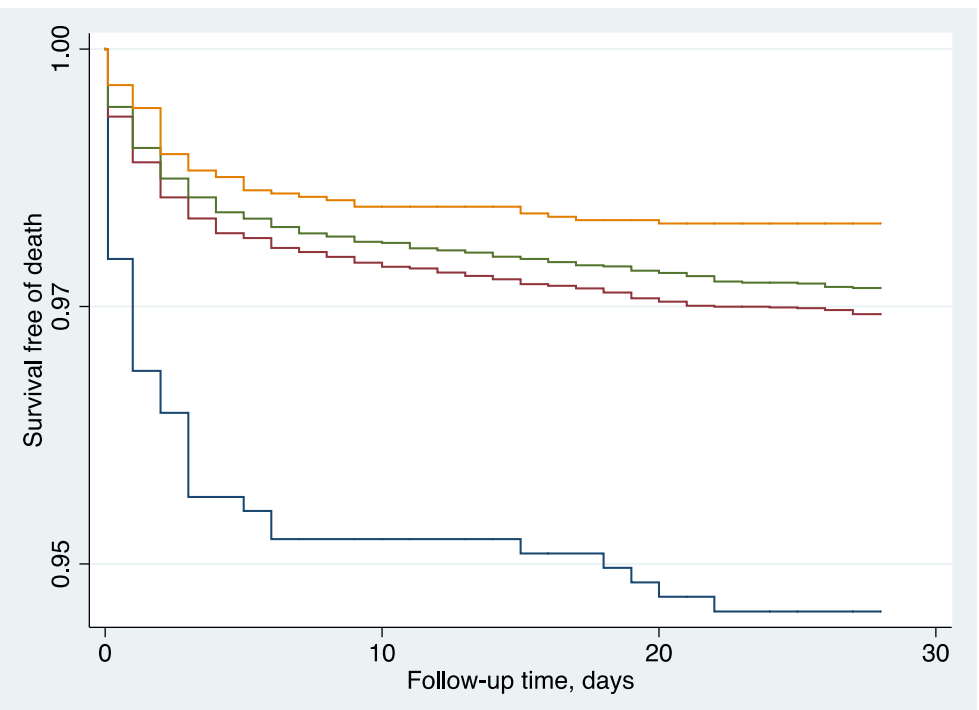

Fig. 2 WHO essential element Kaplan-Meier survival estimates. Received 0 (blue); Received 1 (red); Received 2 (green); Received 3 or 4

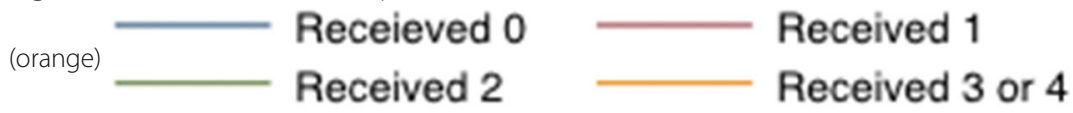

preterm infants, none of which found significant impacts on mortality associated with delayed cord clamping. Those analyses reported that in preterm infants, delayed cord clamping was associated with a significant decrease in the need for transfusions, intraventricular hemorrhage and necrotizing enterocolitis [17, 29]. These outcomes were not assessed in this study, but may be considered in recommendations in the future.

The study's strengths are the size, completeness, short recall period and regular follow-up schedule of the parent trial. Additionally, the amount of information collected allowed for adjusting for multiple potentially confounding variables. Furthermore, surveys were conducted as soon as appropriate after births and deaths of infants to reduce potential recall bias.

The data for this analysis was collected using primarily maternal recall (few instances of family member recall for sections of the newborn verbal autopsy questionnaire), which is a potential limitation because maternal recall of events around labor and delivery has been shown to have varied validity. Previous validation studies that assessed maternal recall of three elements (DCC not examined) did not have high accuracy (AUC > 0.70); the AUCs ranged from $0.50-0.63$, indicating poor to moderate validity [30-32]. These studies were conducted in facilities where the validity of these recall measures may have been worse than for home births where the mother may have had more ability to see and know what was happening to the infant right after birth. In this study, the elements DCC and ITD had the highest numbers of "don't know" responses (Supplemental Table 8), both of which a woman is likely to know if it occurred if she is told by a health care provider or family member present at delivery. However, there was no assessment of the validity of the maternal recall for home versus facility births in the parent study.

According to two reports, information on these elements collected in household and facility surveys to measure coverage is sparse, if collected at all [6,33]. The fact that the parent trial collected information on these elements allowed us to demonstrate that the four elements together have the potential to make a sizable impact on neonatal mortality. Even though the magnitude of the reduction was not necessarily significant for all elements individually, there was a demonstrated dose response relationship between the number of the four elements received and reduced risk of mortality. Therefore, routine data on the coverage of the four elements, individually and the number received per infant, should be collected to inform programmatic efforts and health systems. This routine reporting of the four elements can act as a status update for health system functioning and goals for coverage can be set in order to reach the SDG's neonatal mortality target of 12 deaths per 1000 live births [2].

As the majority of the 75 countries did not reach the MDG goals for child survival, it is apparent that further action is needed to achieve the SDGs. Determining how interventions interact, rather than exclusively studying them in isolation, can inform design and implementation of health programs. The results of this study demonstrate that these four interventions are associated with 
improved outcomes for newborns in a dose response way. Furthermore, these findings support designing future programs for newborn care with a multidimensional approach in order to improve newborn and child survival.

\section{Supplementary information}

Supplementary information accompanies this paper at https://doi.org/10. 1186/s12884-020-03239-6.

Additional file 1. Supplementary materials (Supplementary Tables 1-8, Supplementary Figs. 1, 2a-2d).

\section{Abbreviations}

DCC: Delayed cord clamping; EIB: Early initiation of breastfeeding; HR: Hazard Ratio; ITD: Immediate and thorough drying; MDG: Millennium Development Goal; SDG: Sustainable Development Goal; SSC: Skin to skin contact; WHO: World Health Organization

\section{Acknowledgements}

The Nepal Nutrition Intervention Project- Sarlahi (NNIPS) team are acknowledged for their immense amount of work on conducting the Nepal Oil Massage Study (NOMS) parent trial.

\section{Authors' contributions}

LM, SK, SL, JT and JK were all involved with the conception, design, and acquisition of data. EB and JK developed the analysis plan and EB conducted the analysis and interpreted the data. EB drafted the manuscript and JK and JT edited the manuscript. All authors approve the submitted version of this manuscript.

\section{Funding}

The study was supported by the National Institutes for Child Health and Development (HD060712) and the Bill \& Melinda Gates Foundation (OPP1084399). Analyses for this publication were supported by R01 HD092411. The funders did not have a role in the design of the study, the data collection, nor the analysis, interpretation and writing of the manuscript.

\section{Availability of data and materials}

The datasets used for the analysis are available from the corresponding author upon reasonable request.

\section{Ethics approval and consent to participate}

The parent study was approved by the Institutional Review Board of the Johns Hopkins Bloomberg School of Public Health (Baltimore, Maryland) and the Ethical Review Committee of the Institute of Medicine, Tribhuvan University (Kathmandu, Nepal). All participants in the parent study gave consent.

\section{Consent for publication}

Not applicable.

\section{Competing interests}

The authors declare no competing interests.

\section{Author details}

${ }^{1}$ Department of International Health, Johns Hopkins Bloomberg School of Public Health, 615 N. Wolfe Street, Baltimore, MD 21205, USA. ${ }^{2}$ Nepal Nutrition Intervention Project - Sarlahi (NNIPS), Nepal Eye Hospital Complex PO Box 335, Tripureshwor, Kathmandu, Nepal. ${ }^{3}$ Department of Global Health, Milken Institute School of Public Health, George Washington University, 950 New Hampshire Avenue, Washington, DC, USA.
Received: 28 May 2020 Accepted: 2 September 2020

Published online: 16 September 2020

\section{References}

1. Hug L, Alexander M, You D, Alkema L. Estimation UNI-aGfCM. National, regional, and global levels and trends in neonatal mortality between 1990 and 2017, with scenario-based projections to 2030: a systematic analysis. Lancet Glob Health. 2019;7(6):e710-e20.

2. Sustainable Development Goal 3 Available from: https://sustainabledevelopment un.org/sdg3. Accessed 28 Mar 2020

3. Victora CG, Requejo JH, Barros AJ, Berman P, Bhutta Z, Boerma T, et al. Countdown to 2015: a decade of tracking progress for maternal, newborn and child survival. Lancet (London, England). 2016;387(10032):2049-59.

4. Commission NP. The millennium development goals, final status report, 2000-2015. 2016.

5. Grove J, Claeson M, Bryce J, Amouzou A, Boerma T, Waiswa P, et al. Maternal, newborn, and child health and the Sustainable Development Goals--a call for sustained and improved measurement. Lancet (London, England). 2015;386(10003):1511-4.

6. Madaj B, Smith H, Mathai M, Roos N, van den Broek N. Developing global indicators for quality of maternal and newborn care: a feasibility assessment. Bull World Health Organ. 2017:95(6):445-521.

7. Perlman JM, Wyllie J, Kattwinkel J, Wyckoff MH, Aziz K, Guinsburg R, et al. Part 7: neonatal resuscitation: 2015 international consensus on cardiopulmonary resuscitation and emergency cardiovascular care science with treatment recommendations (reprint). Pediatrics. 2015:136(Suppl 2): S120-66.

8. Ersdal HL, Mduma E, Svensen E, Perlman JM. Early initiation of basic resuscitation interventions including face mask ventilation may reduce birth asphyxia related mortality in low-income countries: a prospective descriptive observational study. Resuscitation. 2012;83(7):869-73.

9. Mullany LC. Neonatal hypothermia in low-resource settings. Semin Perinatol. 2010:34(6):426-33

10. Lunze K, Bloom DE, Jamison DT, Hamer DH. The global burden of neonatal hypothermia: systematic review of a major challenge for newborn survival. BMC Med. 2013;11:24.

11. Sodemann M, Nielsen J, Veirum J, Jakobsen MS, Biai S, Aaby P. Hypothermia of newborns is associated with excess mortality in the first 2 months of life in Guinea-Bissau, West Africa. Trop Med Int Health. 2008;13(8):980-6.

12. Kumar V, Shearer JC, Kumar A, Darmstadt GL. Neonatal hypothermia in low resource settings: a review. J Perinatol. 2009:29(6):401-12.

13. Moore ER, Bergman N, Anderson GC, Medley N. Early skin-to-skin contact for mothers and their healthy newborn infants. Cochrane Database Syst Rev. 2016;11:CD003519.

14. Sharma A. Efficacy of early skin-to-skin contact on the rate of exclusive breastfeeding in term neonates: a randomized controlled trial. Afr Health Sci. 2016;16(3):790-7.

15. Bergman NJ, Linley LL, Fawcus SR. Randomized controlled trial of skin-toskin contact from birth versus conventional incubator for physiological stabilization in 1200- to 2199-gram newborns. Acta paediatrica (Oslo, Norway : 1992). 2004;93(6):779-85.

16. WHO Guideline: Delayed umbilical cord clamping for improved maternal and infant health and nutrition outcomes. Geneva: World Health Organization; 2014

17. McDonald SJ, Middleton P, Dowswell T, Morris PS. Effect of timing of umbilical cord clamping of term infants on maternal and neonatal outcomes. The Cochrane database of systematic reviews. 2013;7:CD004074.

18. Mercer JS. Current best evidence: a review of the literature on umbilical cord clamping. Journal of midwifery \& women's health. 2001;46(6):402-14

19. Sankar MJ, Sinha B, Chowdhury R, Bhandari N, Taneja S, Martines J, et al. Optimal breastfeeding practices and infant and child mortality: a systematic review and meta-analysis. Acta paediatrica (Oslo, Norway : 1992). 2015; 104(467):3-13.

20. Patel A, Bucher S, Pusdekar Y, Esamai F, Krebs NF, Goudar SS, et al. Rates and determinants of early initiation of breastfeeding and exclusive breast feeding at 42 days postnatal in six low and middle-income countries: A prospective cohort study. Reprod Health. 2015;12(Suppl 2):S10.

21. Mullany LC, Katz J, Li YM, Khatry SK, LeClerq SC, Darmstadt GL, et al. Breastfeeding patterns, time to initiation, and mortality risk among newborns in southern Nepal. J Nutr. 2008;138(3):599-603. 
22. Debes AK, Kohli A, Walker N, Edmond K, Mullany LC. Time to initiation of breastfeeding and neonatal mortality and morbidity: a systematic review. BMC Public Health. 2013;13(Suppl 3):S19.

23. Mullany LC, Darmstadt GL, Khatry SK, Tielsch JM. Traditional massage of newborns in Nepal: implications for trials of improved practice. J Trop Pediatr. 2005;51(2):82-6.

24. Requejo JH, Newby H, Bryce J. Measuring coverage in MNCH: challenges and opportunities in the selection of coverage indicators for global monitoring. PLoS Med. 2013;10(5):e1001416.

25. Akter T, Dawson A, Sibbritt D. What impact do essential newborn care practices have on neonatal mortality in low and lower-middle income countries? Evidence from Bangladesh. J Perinatol. 2016;36(3):225-30.

26. Ellis M, Manandhar DS, Manandhar N, Wyatt J, Bolam AJ, Costello AM. Stillbirths and neonatal encephalopathy in Kathmandu, Nepal: an estimate of the contribution of birth asphyxia to perinatal mortality in a low-income urban population. Paediatr Perinat Epidemiol. 2000;14(1):39-52.

27. Conde-Agudelo A, Diaz-Rossello JL. Kangaroo mother care to reduce morbidity and mortality in low birthweight infants. Cochrane Database Syst Rev. 2016;8:CD002771.

28. Lawn JE, Mwansa-Kambafwile J, Horta BL, Barros FC, Cousens S. 'Kangaroo mother care' to prevent neonatal deaths due to preterm birth complications. Int J Epidemiol. 2010;39(Suppl 1):i144-54.

29. Rabe H, Diaz-Rossello JL, Duley L, Dowswell T. Effect of timing of umbilica cord clamping and other strategies to influence placental transfusion at preterm birth on maternal and infant outcomes. Cochrane Database Syst Rev. 2012;8:CD003248.

30. Blanc AK, Warren C, McCarthy KJ, Kimani J, Ndwiga C, RamaRao S. Assessing the validity of indicators of the quality of maternal and newborn health care in Kenya. J Glob Health. 2016;6(1):010405.

31. Blanc AK, Diaz C, McCarthy K, Berdichevsky K. Measuring progress in maternal and newborn health care in Mexico: validating indicators of health system contact and quality of care. BMC Pregnancy Childbirth. 2016;16:255.

32. Stanton CK, Rawlins B, Drake M, Dos Anjos M, Cantor D, Chongo L, et al. Measuring coverage in $\mathrm{MNCH}$ : testing the validity of women's self-report of key maternal and newborn health interventions during the peripartum period in Mozambique. PLoS One. 2013;8(5):e60694.

33. Flenady V, Wojcieszek AM, Fjeldheim I, Friberg IK, Nankabirwa V, Jani JV, et al. eRegistries: indicators for the WHO essential interventions for reproductive, maternal, newborn and child health. BMC pregnancy and childbirth. 2016;16(1):293.

\section{Publisher's Note}

Springer Nature remains neutral with regard to jurisdictional claims in published maps and institutional affiliations.

Ready to submit your research? Choose BMC and benefit from:

- fast, convenient online submission

- thorough peer review by experienced researchers in your field

- rapid publication on acceptance

- support for research data, including large and complex data types

- gold Open Access which fosters wider collaboration and increased citations

- maximum visibility for your research: over $100 \mathrm{M}$ website views per year

At $\mathrm{BMC}$, research is always in progress.

Learn more biomedcentral.com/submissions 